A management plan for the area was developed with communities in April 2015 and has been submitted to the local Direction Régionale de l'Environnement et des Forêts. It is hoped this work can successfully replicate progress in the west of the country.

Victoria PRICE Fauna \& Flora International, Cambridge, UK. E-mail victoria.price@fauna-flora.org

JULIE RAZAFIMANAHAKA and DAUDET ANDRIAFIDISON Madagasikara Voakajy, Antananarivo, Madagascar

\section{Slow loris arm key-rings}

In March 2015, after attending a workshop that was partly aimed at finding solutions to the ongoing illegal wildlife trade along China's southern borders, we had the opportunity to visit the Chinese border town of Daluo and its sister-town across the border in Myanmar, Mong La. Based on research conducted during 2006-2014 Nijman et al. (Primate Conservation, 2014, 28, 139-142) identified Mong La as a major trading centre for Bengal slow lorises Nycticebus bengalensis. The Bengal slow loris is categorized as Vulnerable on the IUCN Red List, partially because of rampant illegal trade, and is protected under both Myanmar and Chinese law. International trade in all eight species of slow loris is prohibited as the genus is listed in Appendix I of CITES, to which both Myanmar and China are signatories. In Mong La we observed two live Bengal slow lorises, two freshly killed, 15 skeletons, three skins, five slow loris arms and three bundles of 15 slow loris arms turned into key-rings, all openly for sale. Combined, these represent the remains of at least 32 Bengal slow lorises. We did not observe any Bengal slow lorises in Daluo-the market contained low numbers of wildlife, with the traders informing us of recent heightened presence of enforcement agency's staff, most likely in anticipation of the international workshop-but in July 2014 Axel Hofford, a journalist with the Guardian newspaper, photographed three (potentially up to five) slow loris key-ring chains in Daluo. Trade in Mong La is geared towards the Chinese market, with most wildlife observed in Daluo originating from the Mong La market across the border. The trade in slow lorises in Mong La and Daluo is in violation of Myanmar and Chinese domestic legislation and also of CITES regulations. The use of Bengal slow loris arms and other body parts in traditional Asian medicine is well known to us. We have seen a multitude of animal parts being used as key-rings, including the tails of many mammal species, and live newts, freshwater turtles and fish, each in their own little plastic container. We have not, however, previously seen slow loris arms in use as key-rings (we saw none during earlier visits to Mong La). Could our observations in Mong La and Daluo be the early signs of an emerging trend?

VINCENT NIJMAN and K.A.I NEKARIS Oxford Brookes University, Oxford, UK. E-mailvnijman@brookes.ac.uk

NABAJIT DAS Primate Research Centre NE India, Guwahati, India

MINGXIA Zhang Center for Integrative Conservation, Xishuangbanna Tropical Botanical Garden, Chinese Academy of Sciences, Yunnan, China

\section{Conserving the world's rarest ape: action planning for the Hainan gibbon}

The Critically Endangered Hainan gibbon Nomascus hainanus is the rarest ape and possibly rarest mammal species, comprising a single population of c. 25 individuals in Bawangling National Nature Reserve, Hainan, China. The species occurred historically across Hainan, with an estimated population of c. 2,000 in the 1950s, but experienced a precipitous decline during the 2oth century driven by hunting and extensive habitat loss. Periodic surveys since 2003 have failed to locate any individuals outside the Reserve, and there are no captive populations.

Research over the past 3 decades has clarified key aspects of Hainan gibbon biology, behaviour and ecology, and conservation legislation is in place to protect the last population: Bawangling was gazetted as a protected area in 1980 and the species was designated a State 1 Protected Species under the 1988 Chinese Wildlife Protection Law. The first Conservation Action Plan for the species was produced in 2005 , focusing primarily on threat abatement. Subsequent management activities have included efforts to protect and restore gibbon habitat, and there has been some apparent growth in the gibbon population. However, the tiny size of the sole population threatens the long-term survival of the species.

To promote effective conservation of the Hainan gibbon a conservation planning workshop was held during 18-20 March 2014 in Bo'ao, Hainan. This international workshop was organized by the Zoological Society of London in cooperation with the Hainan Bawangling National Nature Reserve Management Office and the IUCN Species Survival Commission China Primate Specialist Group, with support from Kadoorie Farm \& Botanic Garden and Fauna \& Flora International, and was facilitated by the IUCN Species Survival Commission Conservation Breeding Specialist Group. Financial support was provided by the Arcus Foundation and the Mohamed bin Zayed Species Conservation Fund. Over 100 stakeholders participated, including experts in gibbon conservation and small population recovery programmes, and representatives 